\title{
Chris Longbottom: 'If you can pick up any disease process and stop it from progressing, you've won'
}

Interview by Kate Quinlan

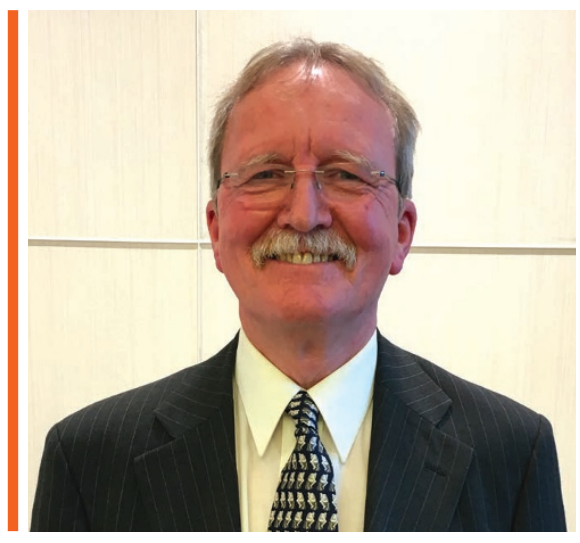

Why did you originally decide to study dentistry?

I was born in 1947 and rationing was still on at that point. In the early 50s rationing was removed and there was suddenly an explosion of confectionery. This hit just at the right time for me - I had a really sweet tooth.

I ended up getting orthodontic treatment and that's what triggered the interest in dentistry, as I spent so much time at the dentist. My first experience was a GA and an extraction but then I just got used to going.

I'm from South Kirkby, a small mining village in South Yorkshire, and was the first person in the family to go to university. Dad worked for the National Coal Board in Doncaster as an administrative assistant and Mum was a dinner lady.

\section{When you were in general practice in the 1970s, how did children's teeth compare with those of child patients today?}

I qualified before fluoride toothpastes, before fissure sealants, before glass ionomers, before composites, before fluoride varnishes - you can imagine what it was like. When I qualified holes were holes - there were big holes in teeth. You weren't hunting for them. Essentially when I started out in the early 70 s, in Scotland anyway - and the areas I worked in were relatively deprived - every

\section{Dr Christopher Longbottom is Assistant Director of the Dental Innovation and} Translation Centre (DITC), King's College London, where he helps develop technology applications for clinical use, principally in dentistry. He has been involved in the application of optical, electrical and ultrasound methodologies to caries detection, dental erosion detection, and monitoring of the developing occlusion. Chris graduated from Dundee in 1971 and after working in general practice, spent 13 years in the Community Dental Service before teaching paediatric dentistry at Dundee as a Senior Lecturer until 2012, after which he moved to King's to help set up the DITC with Nigel Pitts.

7-year-old child had holes in their first permanent molars, full stop, so you spent your time sticking needles in kids and drilling holes in them. They didn't like it. There was a lot of caries not just in the molars but in the anterior teeth as well. An ocean of caries.

Yes children brushed their teeth in those days, but obviously the toothpaste contained no fluoride. The adverts in the 1960s for toothpaste were focused on giving you a 'ring of confidence' - a smile - to keep your teeth looking nice rather than healthy. When Crest came out the adverts shifted to 'no cavities today mum' - an ethos of preventing disease.

In population terms, undoubtedly children's teeth are better today, in the main, but still there are swathes of the population with problems. It depends on the disease level in particular areas, but certainly in Scotland, there is still a lot of caries around and you can map where the caries is. You just have to look at the epidemiology and you know that most of the molars will become DMFT if you just leave them, so you've got to be proactive with prevention.

\section{Did working in the CDS lead you to take a greater interest in paediatric dentistry?}

Absolutely. I worked in three different practices and at the third one, after two or three years, I realised I'd been taught the beginnings of preventive dentistry as an undergrad, but in the NHS in those days you weren't allowed to do any prevention. I can remember two children in particular, two orphans, who had been brought up by their grandparents, they were about eight and ten, and I was restoring their lower anterior teeth - less than $1 \%$ of the population get caries in their lower anterior teeth. There's me, wanting to try and keep these kids healthy, and all I'm paid to do is fill their teeth, chase the disease.

By sheer chance I've been very lucky; just as I was getting disillusioned with the drill-and-fill approach in practice, I got married and the next door neighbour was the daughter of the district dental officer. In conversation I heard that her dad had a job coming up. So I applied and, to cut a long story short, two months later I'm sitting there drinking my tea and there's a knock at the door, and the district dental officer comes in and says you know that job you applied for, do you still want it? I said yes. They had offered the job to someone else but that person had moved to London. So I took the job with the CDS.

In those days you were literally in a clinic and you got on with it, there was no one breathing down your neck, no audits and so on. Fissure sealants and topical fluorides were just coming in and I thought, there is 
a chance here to make a difference. After a couple of years I got moved from what was a fairly affluent area to a post-war housing scheme in deepest, darkest Dundee. It was just a sea of caries and I thought I can either chase this forever or I can try and do something about it and start preventing. So I started preventing as much caries as I could, and that is what I did in that particular post for about 11 years.

I think I did make a difference, as when I knew I was going to leave I checked. I was fortunate in that about half the kids in my patch went to a general practitioner and half of them came to me. Basically I was going to the schools and saying you need treatment - you tried to push them/their parents to bringing them in. Once they were in you could actually say, let's control the disease here. I checked because I saw 50/50 of the patients and I know I was biased but I was quite pleased that I had made the difference in the children I saw.

Caries starts in childhood, so that's when you should start prevention. Lots of kids are anxious, nervous, terrified of the dentist. That is what I am passionate about: you can take a child who is terrified, and because you're not doing anything nasty to them - you can virtually avoid, if you so desire, drilling and needles, if you start early enough. You can actually get that child to enjoy coming to the dentist, and that is priceless.

\section{Did children's teeth continue to improve during the time you worked in the community?}

I saw things transform. When I moved to the CDS in 1974 sealants weren't really mature - there were a few on the market - but they were getting there, and then fluoride toothpaste came in in the mid-70s and saturated the market, and I would see several thousand kids every year and you could see the caries dropping. Then in the early 80 s it sort of levelled off. Just anecdotally, through observation, I could see that the caries levels weren't getting any better.

It was round about that time that a letter was published in the $B D J$ and it was from a general practitioner, not an academic, and it asked 'has anybody noticed that what looks okay on the surface, when you take $\mathrm{X}$-rays, there's caries underneath?' That letter triggered another letter from a practitioner who said 'yes I've noticed that too'. Dentinal caries under what looks like intact surfaces; they called it occult caries. I thought that's absolutely right, but from my perspective, I wasn't getting so much of it, because as soon as the teeth were fully erupted I was sealing them anyway, so there was no chance for the caries to develop that quickly.

\section{Is this what inspired you to undertake research into cariology?}

It triggered my interest in prevention. I actually walked into the dental school in Dundee and spoke to the Dean and said I want to do some research (I wasn't encouraged to do research in the community). The Dean said there's a new guy on the block in the Research Unit, so I walked into Nigel Pitts' office and we just clicked, we had the same approach. So for a couple of years, I dashed down to the dental school at lunchtimes to work with Nigel. Then a job came same position. It worked in the lab and in the clinic. We patented it but it was too expensive to make. So the first lesson I learnt was don't invent something that you can't actually use. You need to make something that the man on the street can use and that the manufacturer can make money out of - commercialisation. So we started working on other things. I am interested in the technology aspect and developing things - how you can solve a problem in a commercially viable way.

\section{What has your involvement been with the development of CALCIVIS?}

When I was at IADR in Baltimore I went to a big bookstore nearby - amongst the popular science section I saw a book on 'glowing genes'. I flicked through and the word calcium jumped out at me. The author had developed a biomarker that luminesces when it comes into contact with calcium

\section{'You can take a child who is terrified and if you start early enough, actually get that child to enjoy coming to the dentist, and that is priceless.'}

up and I decided to go for it, even though I wasn't an academic. As chance would have it, lucky strike again, because Dundee was under threat of closure at the time so there weren't many applicants. They said they would give me a five year contract and if I got a PhD I'd get a permanent job.

I was interested in caries detection and diagnosis and I noticed something when I was working with the curing light that polymerises resins. Instead of the dental nurse holding a shield, which restricts the view, I was wearing goggles, and I noticed that when I shone the light onto the surface of the tooth, the caries on the mesial surface of the molar for example changed colour, and I wondered why. So Nigel and I decided to look into this. I had also started experimenting with separating, teeth using orthodontic separating modules, to detect approximal caries. I looked at every different technology that had ever been thrown at detecting caries and you name it, everything has been thrown at it. This got me talking to physicists and chemists and electrochemists and it opened a whole new world of science.

We developed a helpful bitewing holder which looked like nothing on earth, which ensured that $\mathrm{X}$-rays were always taken in the ions. Caries is basically demineralisation that increases the number of calcium ions. So I thought, we could use this technology for seeing how active lesions are. This was in the mid-2000s. So I bought the book, got home and found that the man who had developed the biomarker was based in Edinburgh University. I bought some of the material from the University spin-off company, called Lux, but couldn't get it to work, so I went to Edinburgh with some teeth and thought can we identify where active caries is in the lab using this material? It worked so we started working on the development of it. Then we started working towards creating a prototype. The financial crash came along so the company research was being slimmed down, but the new chief exec said 'can we park the development of the technology for a while until there is more money to develop it?' He managed to raise the funds to start a new company, CALCIVIS, which is the commercialisation vehicle for the product that Nigel and I helped develop.

The CALCIVIS device may also be of some value in detecting and monitoring erosion. The CALCIVIS imaging system is currently undergoing clinical studies with a view to launching at the end of this year. 


\section{Can you tell us about any of the other applications for technology that you are working on?}

We've got several things on the go. One is a remineralisation technology. At an Indiana conference that we were involved with we had a meeting parallel to one held by the ICDAS group [the International Caries Detection and Assessment System group], and a colleague in paediatric dentistry (from Melbourne, which has fluoridated water) was presenting some work of his on the treatment of fluorosis using a new material called Recaldent (CPP-APP). And I knew I could do this treatment better! We'd been working on an ac impedance technology for caries detection during my $\mathrm{PhD}$ it was blindingly obvious that it was important to measure the electrical properties of teeth for caries detection. As the tooth demineralises it takes in more fluid and becomes more electrically conductive. So I went to the electrochemists in nearby St Andrews University and we started collaborating on developing a caries detection device. We went from an initial lab experiment in 1996 to putting a device on the market in 2007. So when I saw the Recaldent work, from what I had learned from the electrochemists, I realised that one could potentially use electrical methods to rapidly put mineral, lost due to caries, back into teeth.

We are currently working to commercialise this remineralisation technology via a spin-out company from King's.

We are also looking at the use of a near-infrared imaging technology for imaging teeth without using X-rays and obtaining 3D data in the images. We have been working on this for several years with a Professor of Physics, John Girkin, who is now at Durham University, and are hoping to commercialise this technology.

\section{Do you see many of these technologies being widely used in UK dental practices?}

Hopefully in the long term yes. I think it's fair to say they're at the preventive end of the market, the idea being to pick up the disease right at the early stage so that it can be monitored and the disease process reversed. In general terms the NHS as it stands at the moment is not geared towards that; the fundamental core of it is restoring the effects of the disease. The focus of interest to start with would be from dentists in private practice who can focus on prevention. But ultimately this should be of interest to all dentists.

If you can pick up any disease process and stop it from progressing - stopping teeth from cavitating - you've won.

\section{Were you strict with your own children's diets and oral health routines when they were young?}

I flossed my kids' teeth from the age of six months until they were 12. My children just got used to it and it became routine.

When parents say 'they won't let me brush his teeth' I say 'does he like having his hair washed?' You wash his hair, so brush his teeth! My wife [a public health nutritionist who was involved with the Tristan da Cunha study published in the BDJ in 2003; 195: 159-162] was superb. We had set times for sweets, usually weekends. Three or four Easter eggs lasted almost until the following Easter. My wife was able to control our children's sugar intake and it worked.

As an undergrad we were taught to start seeing children when they were three because they are then able to cooperate. We were really fortunate in Dundee in the early 70s in having a very far-sighted district dental officer. When medical screening was introduced, children were seen at regular intervals from birth and we got in there and saw children too, from 20 weeks, just before they got their first teeth. This is when you need to reach the mums; at this point they are primed to do what is best for their children.

It can be a battle, but kids aren't going to brush their teeth on their own. They won't be able to do it properly until they're seven or eight.

\section{If you hadn't gone into dentistry, what would have been your Plan B?}

I've never had a career plan at all! I qualified in December '71 and when I was a dental student I had read an article on JFK's assassination and I got interested in it. I was one of the few people who actually bought the Warren Report and the additional 26 volumes of evidence in 1967 - there is no index so you just have to read them to find what's in them. I started writing to people in the States as I was interested in the forensics and I thought, I think I know how it occurred, so I started writing a manuscript. I hadn't quite finished it when I qualified so thought I would take two months off to finish it. After about six weeks of working on it the doorbell rang and a guy I'd never seen before in my life said, 'Have you just qualified as a dentist? Would you come and work for me?' So I said 'okay'. So twice I have had people ring my doorbell and offer me jobs. I just followed my nose and ended up an academic, which I had never dreamed of. There wasn't even a plan A, never mind a plan B. 